\title{
Feedback Environment and Creativity in Education Organizations
}

\author{
Ying-Leh Ling (Corresponding author) \\ School of Educational Studies, Universiti Sains Malaysia, Penang, Malaysia
}

Fairuz Ismail

Malim Nawar Secondary School, Perak Darul Ridzuan, Malaysia

Abdul Ghani Kanesan Abdullah

School of Educational Studies, Universiti Sains Malaysia, Penang, Malaysia

Received: May 12, 2015 Accepted: June 16, 2015 Published: August 3, 2015

doi:10.5296/ire.v3i2.7585 URL: http://dx.doi.org/10.5296/ire.v3i2.7585

\begin{abstract}
This study aims to examine the relationship between feedback environment practices and creativity in the educational organizations. This study is a quantitative study. A total of 40 polytechnic students from Polytechnic Kuching Sarawak are randomly selected to participate in this study. Data were obtained using a set of questionnaire consisting of three parts. The data obtained were analyzed descriptively and inferentially. Inferential analysis involves $t$ test and Pearson correlation. The findings have shown that the level of feedback environment based on students' perception is high. Simultaneously, the level of creativity among the students is also high. The findings indicated that there is no significant difference in feedback environment between genders. Furthermore, the study also showed a significant and positive relationship between feedback environment and students' creativity. The results of this study have several implications directly to the formation of high-quality students as feedback environment and students' creativity are interrelated and inseparable in educational organizations.
\end{abstract}

Keywords: Feedback environment, Creativity, Education organization 


\section{Introduction}

Development of human capital is an important element that should be emphasized in line with the framework of our country towards achieving Vision 2020 and thus it becomes more competitive at international level. Hence, to develop human capital which is understanding, innovative, and balanced in terms of emotional, physical, intellectual, and spiritual, we should not underestimate one's element of creativity. This is because in the context of Malaysia as an emerging country and aspires to become a developed country, creative individuals are highly desired. Thus, both educators and educational organizations should focus on creating a feedback environment to foster creativity among students. The failure of educational organizations to act would prevent countries from achieving a developed nation status by 2020. In this case, Amabile and Gryskiewiez (1987) have described that constructive feedback can enhance creativity. In addition, Vallerand and Reid (1984) also found competent and intrinsic motivation of college students can be enhanced by positive feedback. Higher competency and intrinsic motivation of students would be able to form more creative students. Therefore, researchers assume that the establishment of feedback from educators is expected to increase students' creativity.

\section{Literature Review}

\subsection{Feedback Environment}

One of the responsibilities of a leader is to lead his followers continuously to improve their performance. Shea and Howell (1999) had declared the participants under the leadership of non-transformational leaders have different performance depending on whether they receive feedback tasks. This feedback shows elements that support learning is more likely to improve performance significantly. Constructive feedback and evaluation elements are considered as important components of the performance management system (Aguinis, 2009). Therefore, emphasis is placed on the development of organizational environment that supports interaction processes in organization feedback. An open and encouraging working environment should include continuous feedback channeling that can affect the performance of the followers of the organization. This is because the situation in which no feedback was given to the followers is seen as a weak psychological condition as it is difficult to measure reward to the achievement of the goals. Hence, the environment feedback has to create the feedback process among the leaders of daily followers as well as among the followers other than formal feedback sessions for performance evaluations conducted (Steelman, Levy, \& Snell, 2004).

Steelman et al. (2004) has identified seven dimensions to determine the feedback process in the organization. Through the factor analysis conducted on the data collected, a total of six dimensions of environmental feedback have been identified in the context of Malaysia, namely (a) The credibility of the source of feedback, (b) The quality of feedback, (c) Feedback delivery, (d) Constructive feedback, (e) Availability of feedback, and (f) Encourage seeking for feedback. Dimension of unfavorable feedback has been removed in the context of Malaysia. Dimension for the credibility of the feedback source refers to feedback resource expertise and trust of receiver feedback. To enable recipients responded get maximum effect 
desired, the feedback needs to have high reliability and gain the confidence of recipients respond. Furthermore, the response also refers to the quality of feedback given consistently in all periods, specific, and is seen as more useful and helpful. Aguinis, Gottfredson, and Joo (2012) have emphasized providing feedback to a more constructive approach based on the strength of workers and not by workers' mistakes. Thus, employees see the feedback provided by employers to help them achieve the targets set. In other words, employees see the usefulness of the feedback given by their leaders as constructive feedback.

Followers constantly receive feedback from their leaders from time to time to improve their performance. Thus, access to the feedback must be established either the leader-follower or among the followers. In this study, the availability of resources is to look at the frequency response of workers to contact and / or colleagues for feedback. A duty of a leader is to encourage followers' behavior to seek feedback. This is in line with the opinion of Williams, Miller, Steelman, and Levy (1999) in which one of the important determinants of workers seeking feedback frequency is depending on the extent to which leaders encourage among his followers.

\subsection{Definition and Concept of Creativity}

The concept of creativity is multi-dimensional. Thus, previous researchers tended to identify and understand the creativity by each approach in their study. $\mathrm{Ng}$ (2001) describes four approaches in the study of cognitive creativity, personality, psycho-social, and systems. Cognitive approach tries to understand mental processes that underlie creative thinking. Based on the model Geneplore (Ward, Smith, \& Finke, 1999), there are two phases in a process of creative thinking which the generation phase and exploration phase are. In the generation phase, an individual will develop mental representations that have properties which can promote creative meetings. In the exploration phase, the attributes used to generate creative ideas.

In term of personality, through studies on creative people like Einstein, Edison, Picasso, and others, researchers have listed the characteristics of creative people as open to a wide range of experience, broad interests, attracted to the complex ideas, tolerant of ambiguity, risk taking, and self-confidence (Ng, 2001). Next, psycho-social approach tries to understand the relationship between culture and creativity. This is because there are cultural or environmental effects in order to produce superior and creative human resource. This approach also focuses on intrinsic motivation which plays important role in producing creative ideas.

Csikszentmihalyi (1994) describes that creativity to be found in a system consisting of three interconnected parts of an individual rainbow, field, and domain. Domain consists of areas that have procedures and special symbols such as mathematics, architecture, and so on. The second part is a field that consists of all individuals who are responsible for maintaining the domain. Finally, the third part is the people who are trying to restructure conventional elements in the areas in which they are involved. System approach also emphasizes creativity occurs in the context of a culture. 
Ministry of Education (2011) has defined creativity as 'the production of ideas'. It is a conscious effort that involves creative ideas together with the production of creative act on certain concept, approach, characteristics or nature of time. Thus it can be defined as an invention or creation process (Noraihan, Kamilah \& Norhafiza, 2010). Creativity is not just a process of generating new ideas or develops an existing idea, but it's more focused on using the imagination to generate more new ideas. It is a lifestyle, personality, and practice in life, how to implement something and how to thrive (Leo, 2006).

As stated by Mohd. Azhar (2004), the best place to foster creativity such as inquiry, creativity and discovery at various levels of the students is through teaching and learning, whether in formal or non-formal learning. Moreover, creativity is also seen as practice and conduct deliberate or accidental involving concrete and abstract human activity on nature and the environment (Azhar, Mohd. Koharuddin, Mohammad Fauzi, \& Othman, 2006).

In short, all these definitions show creativity is a human thought process that seeks to create and generate new ideas and solve problems by using the power of imagination, creative ideas and creative thinking.

\subsection{Domain Development Framework Creativity}

In line with the government's desire to realize the learning of the $21^{\text {st }}$ century, there are efforts undertaken by the Ministry of Education in developing the creativity of the students starting from the beginning of schooling. In secondary schools, the technical and vocational subjects have certainly done its creativity through project-based learning and problem solving. Accordingly, Creativity Domain Development Framework (CDD) was built on the definition and the factors that affect creativity. The key principles within the framework of CDD are ethics, culture, communication, environment, knowledge, motivation, intellectual and personality which are interrelated (Kementerian Pelajaran Malaysia, 2011).

The four principles underlying the CDD are ethics, culture, communication and the environment. Ethics is the guide of conduct upheld by each student, which is the regulation that can make students have value and integrity as creative and innovative human beings, based on values and noble characters. Next, culture includes values, attitudes / behaviors, beliefs / rituals / traditions, values and celebrations and traditions which are accepted and internalized by members of the public of a nation. Communication is the process of interaction for effective communication of information from the source to the receiver. In addition, the environment is important to the results of individual creativity. Three components that are relevant in the context of the creative process is to encourage creative ideas, creative ideas to promote follow-up and evaluate and reward creative ideas. 


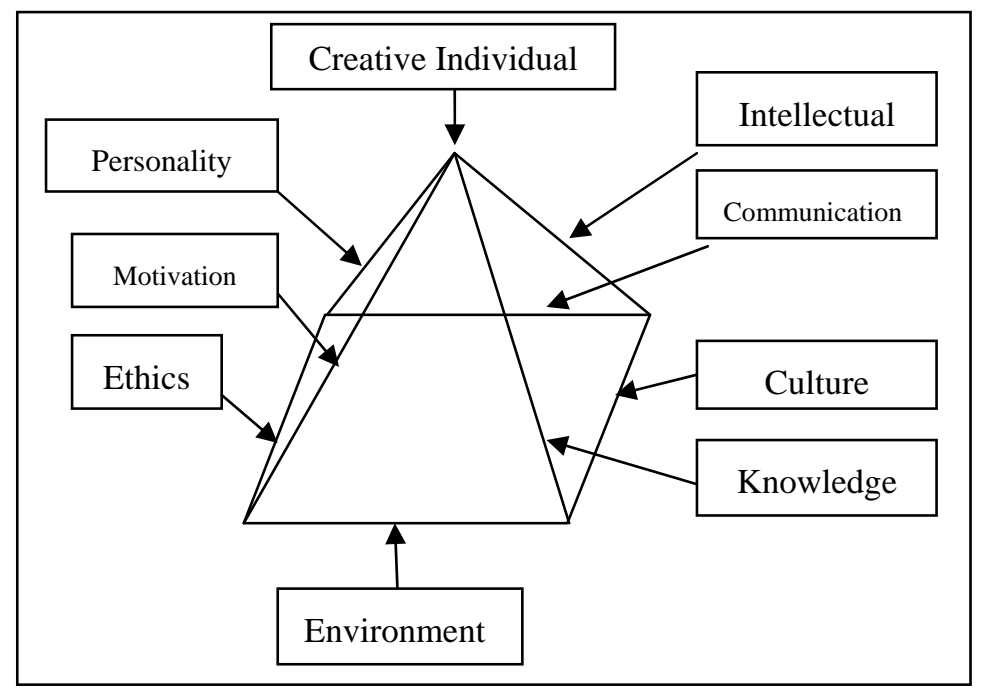

Figure 1. Domain Concepts Creativity Development Framework (CDC, 2011)

Domain Development Framework Creativity depicted in pyramid form where it showed strength, dynamism, strength and stability of a structure. This form leads and coincides with the National Education Philosophy which aims to build balanced, comprehensive and harmonized human beings in terms of their physical, intellectual, emotional and spiritual. In this case, environmental factors have been identified in contributing to the formation of the creativity and imagination of the students in their learning process (Kementerian Pelajaran Malaysia, 2011).

\section{Objectives of the Study}

The objective of this study is to identify the level of environmental feedback and creativity among students of polytechnics. In addition, this study also aims to compare the level of environmental feedback and creativity among the students of polytechnic gender. Next, this study would also identify the relationship between environmental feedback and creativity among students.

\section{Research Methodology}

This research is a quantitative descriptive study through questionnaire. The population consists of all the students who are taking part in their final semester project in Information Technology program in Polytechnic Kuching Sarawak. A total of 40 students were randomly selected to participate in this study. In this study, the independent variable is the environment variable feedback while dependent variable is creativity. The instrument used is the adapted Feedback Environment Scale which consisting 25 items allows the subjects give their views about the feedback environment created by their lecturers in the study. In addition, Creative Thinking Styles test adapted from Chua (2004) with 14 items is used to identify students' creativity. Seven-point Likert scale used in this study. 


\section{Findings and Discussion}

\subsection{The Level of Feedback Environment}

Table 1 shows the mean score from the six-dimensional perception of feedback environment by final year students of the Information and Technology Communication Department at the Polytechnic Kuching Sarawak. All items have been answered by 40 students in the questionnaire. Feedback delivery dimension has earned the highest score of 5.61 while the constructive feedback dimension has received the lowest ranking with a score of mean 5.43. This shows that the students focus on the delivery of the feedback from their lecturer. In addition, the lecturers should respond more constructively to the students. Overall, the level of feedback environment responses by students' perceptions is at high level with the mean score as high as 5.55. The findings also indicated that lecturers should focus on to improve its credibility in responding constructively and consistently to students. Feedback will be created and delivered not only in class but informally to enable students to find and get it.

Table 1. Feedback environment dimension distribution

\begin{tabular}{lcc}
\hline Dimension of Environmental Response & Mean & SP \\
\hline Quality Feedback & & \\
$\quad$ Credibility Source Feedback & 5.55 & .795 \\
$\quad$ Quality Feedback & 5.58 & 1.079 \\
Channeling Feedback & & \\
$\quad$ Feedback Delivery & 5.61 & .965 \\
$\quad$ Feedback Resource Availability & 5.59 & .966 \\
Constructive Feedback & 5.43 & .891 \\
Encourage feedback seeking & 5.51 & 1.033 \\
\hline Total & 5.55 & .876 \\
\hline
\end{tabular}

\subsection{The Level of Creativity among Polytechnic Students}

The results in Table 2 show the distribution of students according to their creativity by items in the questionnaire distributed. All the features listed creativity was reorganized according to the mean value obtained. The results clearly demonstrate the creativity item C9 "I made a guess spontaneously without the need for deep thinking" has received the highest mean score of 5.44. Accordingly, the creativity item C13 "I love painting" has appeared with the lowest mean score of 4.41. Overall, the level of creativity of students in the Polytechnic Kuching, Sarawak is at high level with mean score as high as 5.16. The level of creativity among the students needs to be sharpened so that it brings benefits to them. 
Table 2. Characteristics of polytechnic students' creativity according to questionnaire item distribution

\begin{tabular}{|c|c|c|c|c|c|c|c|c|c|c|}
\hline Item & Creativity Features & 1 & 2 & 3 & 4 & 5 & 6 & 7 & Min & SP \\
\hline \multirow[t]{2}{*}{ C9 } & I made a guess spontaneously & - & - & - & 8 & 13 & 14 & 6 & 5.44 & .98 \\
\hline & without requiring deep thought. & & & & 19.5 & 31.7 & 34.1 & 14.6 & & \\
\hline \multirow[t]{2}{*}{$\mathrm{C} 1$} & I solve problems based on the & - & - & 2 & 9 & 10 & 12 & 8 & 5.37 & 1.18 \\
\hline & $\begin{array}{l}\text { principle that the problems can } \\
\text { be solved in various ways. }\end{array}$ & & & 4.9 & 22.0 & 24.4 & 29.3 & 19.5 & & \\
\hline \multirow[t]{2}{*}{$\mathrm{C} 4$} & I can evaluate a problem from & - & - & - & 10 & 4 & 9 & 8 & 5.37 & 1.07 \\
\hline & multiple perspectives. & & & & 24.4 & 34.1 & 22.0 & 19.5 & & \\
\hline \multirow[t]{2}{*}{$\mathrm{C} 2$} & I always have many ideas of & - & - & 1 & 11 & 11 & 10 & 8 & 5.32 & 1.15 \\
\hline & my own. & & & 2.4 & 26.8 & 26.8 & 24.4 & 19.5 & & \\
\hline \multirow[t]{2}{*}{$\mathrm{C} 7$} & I am able to make a unique & - & - & - & 9 & 14 & 14 & 4 & 5.32 & .93 \\
\hline & $\begin{array}{l}\text { formulation of a statement on } \\
\text { an issue. }\end{array}$ & & & & 22.0 & 34.1 & 34.1 & 9.8 & & \\
\hline \multirow[t]{2}{*}{ C5 } & I always have a lot of & - & - & - & 10 & 14 & 9 & 8 & 5.27 & .95 \\
\hline & interesting ideas on my mind. & & & & 24.4 & 34.1 & 22.0 & 19.5 & & \\
\hline \multirow[t]{2}{*}{$\mathrm{C} 8$} & I often generate ideas for & - & 1 & 1 & 7 & 13 & 15 & 4 & 5.27 & 1.10 \\
\hline & drawing objects. & & 2.4 & 2.4 & 17.1 & 31.7 & 35.6 & 9.8 & & \\
\hline \multirow[t]{2}{*}{ C10 } & I like to judge the authenticity & - & - & 1 & 7 & 18 & 10 & 5 & 5.27 & .98 \\
\hline & of a new design. & & & 2.4 & 17.1 & 43.9 & 24.4 & 12.2 & & \\
\hline \multirow[t]{2}{*}{ C11 } & I can make jokes and people & - & - & 1 & 9 & 15 & 12 & 4 & 5.22 & .99 \\
\hline & laugh easily. & & & 2.4 & 22.0 & 36.6 & 29.3 & 9.8 & & \\
\hline \multirow[t]{2}{*}{ C3 } & I often solve problems using & - & - & - & 13 & 13 & 12 & 3 & 5.12 & .95 \\
\hline & my sixth sense. & & & & 31.7 & 31.7 & 29.3 & 7.3 & & \\
\hline \multirow[t]{2}{*}{ C6 } & I make decisions based on & 1 & 1 & - & 9 & 16 & 10 & 4 & 5.05 & 1.22 \\
\hline & emotion or feeling. & 2.4 & 2.4 & & 22.0 & 39.0 & 24.4 & 9.8 & & \\
\hline \multirow[t]{2}{*}{ C12 } & I am adept at drawing & - & 1 & 3 & 10 & 14 & 9 & 4 & 4.95 & 1.18 \\
\hline & 3-dimensional shape. & & 2.4 & 7.3 & 24.4 & 34.1 & 22.0 & 9.8 & & \\
\hline \multirow[t]{2}{*}{ C14 } & I like music. & 2 & 2 & 3 & 9 & 10 & 7 & 8 & 4.85 & 1.65 \\
\hline & & 4.9 & 4.9 & 7.3 & 22.0 & 24.4 & 17.1 & 19.5 & & \\
\hline \multirow[t]{3}{*}{ C13 } & I love painting. & 3 & 5 & 2 & 7 & 15 & 4 & 5 & 4.41 & 1.72 \\
\hline & & 7.3 & 12.2 & 4.9 & 17.1 & 36.6 & 9.8 & 12.2 & & \\
\hline & Total & & & & & & & & 5.16 & .80 \\
\hline
\end{tabular}

\subsection{Creativity Difference between Genders}

The results in Table 3 show that overall there was no significant difference in creativity between male and female students on a significant level of $p<.05$. This means that both male and female students exhibit the same level of creativity. The findings are consistent with the findings of Hamsiah (2004) and Balan and Ivy (2014) where gender does not affect the students' creativity. This means that creative ability is not subject to either male or female students. In other words, gender does not have any effect in increasing or reducing the creative ideas of students.

Table 3. The results of data analysis for creativity difference between male and female students

\begin{tabular}{ccccccc}
\hline Variable & Gender & Mean & Standard Deviation & $t$ & df & Sig. (2- Tailed) \\
\hline Creativity & Male & 5.15 & .750 & -.051 & 39 & .96 \\
& Female & 5.17 & .864 & & & \\
\hline
\end{tabular}




\subsection{Feedback Environment Difference between Genders}

The results in Table 4 show that overall there was no significant difference of environmental feedback between male and female students on a significant level of $p<.05$. This means that both genders exhibit the same standard of environmental feedback.

Table 4. The results of data analysis for environmental feedback difference between male and female students

\begin{tabular}{ccccccc}
\hline Variable & Gender & Min & Standard Deviation & $t$ & $d f$ & Sig. (2- Tailed) \\
\hline Environmental & Male & 5.49 & .827 & -.421 & 39 & .68 \\
Feedback & Female & 5.61 & .947 & & & \\
\hline
\end{tabular}

\subsection{The Relationship between Feedback Environment with Students' Creativity}

Pearson correlation analysis test results showed a significant relationship between feedback environment and creativity of students. There are six dimensions of environmental feedback which have positive and significant correlation with the students' creativity. In particular, the results of the analysis show that there is a significant positive relationship between students' creativity and credibility of feedback source $(r=.59, p<.05)$, the quality of feedback $(r=.54$, $p<.05)$, delivery feedback $(r=.46, p<.05)$, the availability of feedback $(r=.56, p<.05)$, constructive feedback $(r=.69, p<.05)$, and encourage seeking of feedback source $(r=.52$, $p<.05$ ). The study also shows that there is positive and significant correlation between environmental aspects feedback.

Table 5.

\begin{tabular}{lcccccc}
\hline Variable & Creativity & (b) & (c) & (d) & (e) & (f) \\
\hline Credibility Source Feedback (b) & $.59^{*}$ & & & & & \\
Quality Feedback (c) & $.54^{*}$ & $.89^{*}$ & & & & \\
Delivery Feedback (d) & $.46^{*}$ & $.81^{*}$ & $.89^{*}$ & & & \\
Availability Source Feedback (e) & $.56^{*}$ & $.61^{*}$ & $.75^{*}$ & $.75^{*}$ & & \\
Constructive Feedback (f) & $.69^{*}$ & $.66^{*}$ & $.65^{*}$ & $.61^{*}$ & $.70^{*}$ & \\
Encourage seeking of feedback resource & $.52^{*}$ & $.55^{*}$ & $.57^{*}$ & $.55^{*}$ & $.61^{*}$ & $.86^{*}$ \\
\hline
\end{tabular}

*Significant at .05 level

\section{Study Implication and Conclusion}

In the context of education, creativity is seen as a catalyst for national transformation agenda. Creative individuals are able to produce a brilliant idea which became the core practices and cultural life in the future. The findings have found an environment feedback and creativity has a positive and significant relationship. Therefore, leaders must take action to improve the environment that encourages creativity feedback on student learning. 
The study only involved 40 students from the Polytechnic Kuching Sarawak. Thus, the findings only used as a backup or suggestion to other polytechnics and it cannot be generalized findings. This study directly has implication on the organizations of education in our country starting right from the primary level up to the highest level. With the existence of a significant correlation between environmental feedback with students' creativity, leaders are expected to enhance the environmental feedback to encourage creativity in students' learning. Thus, students who come from the country's education system are the potential students in academic and critical thinking and creative in addressing all aspects of their lives. If the creative thinking skills used on the right track, it will produce individuals who have higher level of knowledge, innovation, personal integrity and superior. This is in line with the current state of education towards the 21st century learning.

\section{References}

Aguinis, H. (2009). Performance management (2nd ed.). Upper Saddle River, NJ: Pearson Prentice Hall.

Aguinis, H., Gottfredson, R. K., \& Joo, H. (2012). Delivering effective performance feedback: The strengths-based approach. Business Horizons, 55, 105-111. http://dx.doi.org/10.1016/j.bushor.2011.10.004

Amabile, T. M., \& Gryskiewiez, S. S. (1987). Creativity in the $R$ \& D laboratory. Technical Report Number 30. Greensboro, NC: Center for Creative Leadership.

Azhar Abd. Hamid. (2004). Kreativiti: Konsep, teori dan praktis. Johor: Penerbit UTM.

Azhar Abd. Hamid, Mohd. Koharuddin Balwi, Mohammad Fauzi Othman, \& Othman A. Kassim. (2006). Reka cipta \& inovasi dalam perspektif kreativiti. Skudai: Penerbit UTM.

Balan Rathakrishnan \& Ivy Lian. (2014, Disember). Perbezaan kreativiti berdasarkan jantina pelajar tingkatan empat di Kota Kinabalu Sabah. Kertas dibentangkan dalam Seminar Kebangsaan Integriti Keluarga 2014, Universiti Malaysia Sabah.

Chua, Y. P. (2004). Creative and critical thinking styles. Serdang: Universiti Putra Malaysia Press.

Csikszentmihalyi, M. (1994). Creativity: Flow and the psychology of discovery and intention. New York: Harpen Perennial.

Hamsiah Binti Saee. (2004). Tahap kreativiti guru Sains dan amalannya dalam pengajaran. Jurnal Penyelidikan MPBL, 5, 14-23.

Kementerian Pelajaran Malaysia. (2011). Buku panduan kreativiti pembangunan dan amalan dalam pengajaran \& pembelajaran. Bahagian Pembangunan Kurikulum, Putrajaya.

Lawrence, S., Pennock, D. M., Flake, G. W., Krovetz, R., Coetzee, F. M., Glover, E., ... Giles, C. L. (2001). Persistence of web references in scientific research. Computer, (2), 26-31.

Leo Ann Mean. (2006). On creativity: Awakening the creative mind. Subang Jaya: Pelanduk Publications. 
Ng, A. K. (2001). Why creators are dogmatic people, "nice” people are not creative and creative people are not “nice”. International Journal of Group Tensions, 30(4), 293-324. http://dx.doi.org/10.1023/A:1012720801682

Shea, C. M., \& Howell, J. M. (1999). Charisma leadership and task feedback: A laboratory study of their effects on self efficacy and task performance. Leadership Quarterly, 10(3), 375-396. http://dx.doi.org/10.1016/S1048-9843(99)00020-X

Steelman, L. A., Levy, P. E., \& Snell, A. F. (2004). The feedback environment scale: Construct definition, measurement, and validation. Educational and Psychological Measurement, 64(1), 165-184. http://dx.doi.org/10.1177/0013164403258440

Vallerand, R. J., \& Reid, G. (1984). On the causal effects of perceived competence on intrinsic motivation: A test of cognitive evaluation theory. Journal of Sport Psychology, 6, 94-102.

Ward, T. B., Finke, R. A., \& Smith, S. M. (1995). Creativity and the mind. Discovering the genius within. New York: Plenum Press. http://dx.doi.org/10.1007/978-1-4899-3330-0

Williams, J. R., Miller, C., Steelman, L. A., \& Levy, P. E. (1999). Increasing feedback seeking in public contexts: It takes two (or more) to tango. Journal of Applied Psychology, 84(6), 969-976. http://dx.doi.org/10.1037/0021-9010.84.6.969

\section{Copyright Disclaimer}

Copyright reserved by the authors.

This article is an open-access article distributed under the terms and conditions of the Creative Commons Attribution license (http://creativecommons.org/licenses/by/3.0/). 